Kafkas Üniversitesi Sosyal Bilimler Enstitüsü Dergisi

Kafkas University Journal of the Institute of Social Sciences

Sonbahar Autumn 2021, Sayı Number 28, 675-690

DOI:10.9775/kausbed.2021.037

Gönderim Tarihi: 23.03.2021

Kabul Tarihi: 15.11.2021

SON DÖNEM OSMANLI TOPLUMUNDA EĞLENCE KÜLTÜRÜ AÇISINDAN SÜNNET DÜĞÜNLERI

\title{
Circumcision Feasts in Terms of Entertainment Culture in the Late Ottoman Society
}

Serap YASUBUĞA

Doktora Öğrencisi, Atatürk Üniversitesi, Edebiyat Fakültesi Tarih Bölümü serapyasubuga@hotmail.com

ORCID ID: 0000-0002-0718-5058

Çalışmanın Türü: Araştırma

$\ddot{O} z$

19 yüzyılda Osmanl Devleti'nde birçok alanda görülen Batıl değişme ve gelişmeler eğlence kültürü üzerinde de etkisini göstermiştir Eğlence kültürünün önemli bir unsuru olan sünnet dügüulerinde de bu değişim ve gelişim görülmüş olup, çocuğa bakış açısının ortaya konması açısından önemli bilgiler sunmuştur. Padişah çocuklarının sünnet dügünlerine de yer verilen Sûr-ı hümâyun ile toplumda sünnet dügünü öncesi hazırllklar, düğün günü etkinlikleri, eğlenceleri, fakir ve şehit aile çocuklarının sünnet ettirildiği toplu sünnet dügünleri dönemin sosyo-kültürel, ekonomik, siyasi durumunu yansıtması açısından sünnet düğ̈̈nlerinin önemini ortaya kaymuştur.

Bu çalışmada birinci elden kaynaklar esas alınarak, Osmanlı Devleti'nde sünnet dügü̈nleri ve ĕglence kültüründeki önemi farkl yönleriyle değerlendirilmiştir.

Anahtar Kelimeler: Sünnet, Eğlence, Çocuk, Toplum, Osmanlı Devleti

Abstract

Western changes and developments in many areas in the Ottoman Empire in the 19th century also had importantimpacts on the entertainment culture. This changes and developments were also observed in circumcision feasts, which were important elements in the entertainment culture, and provided important information in terms of revealing the perspective of the child. Sur- Hümayun, where circumcision feasts of the sultan's children were also included, and preparations, exhibited the circumcision feasts in the society, daily activities during the feasts, the entertainments, the mass circumcision feasts where the children of the poor people and martyrs were circumcised, and the importance of circumcision feasts in terms of reflecting the socio-cultural, economic and political situations during this period. In this study, based on the primary sources, circumcision feasts in the Ottoman Empire and their importance in entertainment culture have been evaluated in all aspects.

Keywords: Circumcision, entertainment, children, society, Ottoman State

\section{GÍRIŞ}

Arapça karşıllğı hitan olan sünnet, erkek cinsiyet organının ucundaki fazla derinin alınması ameliyesini ifade etmekteydi. Sünnet ilkel toplumlarda ve gelişmiş ülkelerde dini kültürel bir şekilde uygulanarak tedavi edici ve hastalık önleyici yönüyle de tıpta yer almıştır. Genellikle Sâmi İbrahimî gelenekle özdeşleşmekle birlikte tarih öncesi dönemlere ve farklı 
coğrafyalara da uzanmaktaydı (Gürkan, 2010, s. 155-156).

Sünnet, Cahiliye devrinde uygulandığ 1 gibi İslamiyet'in ortaya çıkışından sonra Hz. Muhammed tarafından Hz. İbrahim'den geldiği kabul edilerek Müslümanlara da uygulanmıştır (Çağatay, 1972, s. 294). Türkler, İslamiyet'i kabul etmesinin ardından sünneti ilk başta ürkütücü olarak görmelerine rağmen çocuklarına da uygulamışlardır (Bayat, 1982, s. 13). Sağlıklı olduğu için doktorlar tarafından da uygulanan sünnet vesilesiyle gerçekleştirilen sünnet dügünleri (Pakalın, 1972, s. 295) farklı toplum ve devletlerde uygulanarak yüzyıllarca devam etmiştir.

Sünnet düğünlerini yüzy1llarca gerçekleştiren toplumlardan biri de Osmanlı toplumuydu. Osmanlı toplumunda dügünlerle ilgili ayrıntılı bilgiler yenileşme ve değişmenin olduğu 19 . yüzyılda yer almıştır. $\mathrm{Bu}$ yüzyıl öncesinde sünnet düğünleri hakkında bilgiler padişah çocuklarının doğum ve sünnet düğünleriyle, padişah kızlarının düğün törenlerinin anlatıldığg "Surnâme"' adlı eserlerden öğrenilmekteydi (Aynur, 2009, s. 565-566). Sayıları yüzleri bulan şenliklerden 11 tanesi surnâmelere konu olmuştur ${ }^{2}$ (Arslan, 2007, s. 225). Padişah çocuklarının sünnet düğünlerine yer verilerek yabancı devlet adamlarının davet edildiği ve 10-15 gün bazen daha da uzun süre devam eden Sûr-1 Hümâyunlar (Bayat, 1982, s. 53-54) döneminin sosyal hayatı gelenek, görenekleri hakkında önemli bilgiler vermekteydi.

\section{SÜNNET ÖNCESİ HAZIRLIKLAR}

Çocukların sünnet edilmesine karar verilirken toplumda yaygın olan inanışlar etkili olurdu. Osmanlı toplumunda sünnet yaşının belirlenmesinde uğurlu olduğu düşünülerek tek rakamlı yaşlar tercih edilirdi. Mesela, İstanbul'da sünnet edilecek çocuklar için 5-11 yaşları tercih edilmekle birlikte (Göktaş, 1994, s. 113) 1,5-2 yaşından başlayarak 13-14 yaşına kadar olan çocuklarda sünnet ettirilirdi (Bayri, 1953, s. 776). Sünnet düğünlerinde

\footnotetext{
${ }^{1}$ Surnâmeler de şu bilgilere yer verilmiştir: "Düğ̈̈n öncesi yapılan hazırlıkları Ferman çıkarılması, Sûr-ı Hümâyun başlama gününün ve yerinin belirlenmesi, davetiyelerin hazırlanması gönderilmesi, törene katılanların adları ve kimlikleri, yemek hazırlıkları, düğ̈̈n için yapılan harcamalar, sünnet alayının geçişi, cambazları, hokkabazların gösterileri, musiki fasılları, rakkas ve çengilerin gösterileri, gece şenlikleridir' ' (Aynur, 2009, s. 565-566).

2“'Illk müstakil surnâme, Gelibolulu Âlî'nin 1582 yllındaki 'Câmi'u'l-Buhûr DerMecâlis-i Sûr' adlı surnâmesi olup, son surnâme ise, 1858 yllında Abdülmecid'in kızlar Cemile Sultan ile Mahmud Celaleddin Paşanın ve Münire Sultan ile İbrahim Ilhami Paşa evlenmeleri dolayısıyla yapılan dügünü anlatan Nâfi'nin 'Surnâme-i Selâtîn veya Peyâm-ı Sûr’ adlı surnâmesidir’' (Arslan, 2007, s. 225-226).
} 
tek rakamlı yaşlar tercih edilerek düğün günü olarak Perşembe gününe denk getirilirdi (Bayri, 1953, s. 777).

Osmanlı toplumunda çocuk yaşı ve sünnet günü gibi yaygın inanışların yer aldığı sünnet dügünlerinde hazırlıklar çocuklarını sünnet ettirmeye karar veren ailelerin sanatında mahir ve meşhur bir sünnetçi ile görüşüp sünnet gününü kararlaştırmasıyla başlardı (Apaydın, 2018, s. 24).

Sünnet günü kararlaştırıldıktan sonra, davetiyeler hazırlanıp akraba ve tanıdıklara verilerek dügüne davet edilirdi. Bu davetleri özellikle sünnet olacak çocuğun annesi hanımların bizzat evlerine giderek veya aracılar göndererek gerçekleştirirdi. Bu davetler için kadınlar kendi tabirlerince “okuyucuya çıktı" derlerdi (Abdülaziz Bey, 1995, s. 40). Sünnet dügünleri açısından bazen de davetiye yerine sünnet olacak çocuk sünnet dügününden bir hafta önce akraba, komşulara götürülüp el öptürülerek düğün daveti yapılırdı (Göktaş, 1994, s. 114). Sünnet düğünlerinde davetiyelerin yanı sıra halkı bu düğünlere davet eden biletler basılarak, ilanlara yer verilirdi. İkdam gazetesinin “Mükemmel Sünnet Düğünü'” başlıklı ilanda, 4 gün 4 gece sürecek olan sünnet düğününe katılım için bilet alınması, uzaktan dahi izlenebilineceği (İkdam, 13 Ağustos 1920, Sayı: 8430) belirtilerek eğlence kültürü açısından sünnet düğününe verilen önem ortaya konulmuştur.

Sünnet düğünleri için genellikle yazın evin bahçeleri tercih edilerek bahçelere çadırlar kurulurdu (Göktaş, 1994, s. 114). Bu çadırlar sünnetten birkaç gün önce düğünün yapılacağı bahçede büyük çadırların etrafına toplu sünnetler vesilesiyle karyolaların yer aldığı (Ülkütaşır, 1979, s. 5) küçük çadırlar yerleştirilirdi. Karyolalar ipek sırmalı yorganlar, bürümcük çarşaflar ve sırmalı baş yastıkları ile süslenirdi. Bunun yanında sünnet yatakları dönemin şartları ve hane sahibinin imkânları nispetinde farklı şekilde de süslenebilirdi (Apaydın, 2018, s. 25).

Sünnet dügünlerinde hazırlık açısından çocuk kıyafetleri de önemli yer tutmaktaydı. Çocukların beline sarılması için beyaz ipekten kumaş kuşak yapılır (Abdülaziz Bey, 1995, s. 43) başa giymesi için sünnet takkesi dikilirdi (Göktaş, 1994, s. 113). Sünnet çocuklarına mavi atlastan üzeri nazarlıklı takkelerden (Celâl, 1946, s. 35) önce fes, külah, kavuklar giydirilir ve serpuşları türlü türlü süsler, elmaslar ve gelin telleri ile süslenirdi. (Koçu, 1969, s. 211). Çocukların sünnet düğününde dışarıda giyecekleri şalvar, şal kuşak ve çuka cübbe, ince düğmeli kavuktan ibret kıyafetlerin yerini devletçe benimsenen resmi forma taklit edilerek göğüs ve arkası sırmalı setri ile sırma şeritli pantolon ve küçük bir kılıçtan ibaret kıyafetler giydirilerek yaygınlık kazanmıştır (Abdülaziz Bey, 1995, s. 44). 
Sünnet hazırlıkları çocukların yanı sıra kadınlar içinde önem taşımaktaydı. Kadınlar sünnet öncesi Kapalıçarşı'daki tuhafiyecilerden, kuyumculardan, saatçilerden, çanakçılardan Eyüp'teki oyuncakçılardan alışveriş yaparak ve hediyeler alarak hazırlıkları tamamlanmaya çalışırlardı (Ekrem\&Fehim, 1945, s. 25).

Sünnet düğününden bir gün önce çocuğun hamama götürülerek yıkanması, sağ eline kına yakılması ve çocukların tepelerindeki bir tutam saçın hiç kesilmeden örülmesi toplum tarafından benimsenmiş sünnet öncesi hazırlıklardandır (Göktaş, 1994, s. 114).

\section{DÜĞÜN MERASIMMLERI}

Düğün günü sünnet olacak çocuğun ailesi erkenden kıyafet, yemeiçme gibi bütün hazırlıklarını tamamlayıp misafirleri karşılayarak sünnet düğününe hazır duruma gelirlerdi (Abdülaziz Bey, 1995, s. 44-46).

Osmanlı toplumunda 19. yüzyılın ortalarına kadar sünnet çocuklarının süslenmiş atlara bindirilerek davul zurna kasideler eşliğinde sokak sokak dolaştırılması âdettendi (Göktaş, 1994, s. 114). Bu âdet şu şekilde gerçekleştirilirdi:

"Sünnet olacak çocuklar kyyafetleri giydirilip başlarına elmas dallar takılarak, en önde mektep arkadaşları ile hazırlanmış olan atlara binerek erkek çocuklar asker safları gibi arkasında ilahici çocuklar onların arkasında atlı hane sahibinin çocuğu ve sünnet olacak diğer çocuklar ikişerli olarak yer aldıkları grup şeklinde hareket edip ilahiler okunarak belirlenen sokaklar dolaştırılırdı"’3 (Abdülaziz Bey, 1995, s. 46-47).

İstanbul'da sünnet düğünlerinde çocuklar açısından önemli âdetlerden biri de türbe ziyaretleriydi. Çocuklar Üsküdar tarafinda Aziz Mahmud Efendi Türbesi ziyaret ettirildiği (Felek, 1974, s. 105) gibi halk arasında yaygın olan inanıştan hareketle Eyüp Sultan'ın çocukları sevdiğine inanılarak çocuklar mektebe başladığı gün olduğu gibi sünnet ettirileceği

\footnotetext{
3،Sünnet düğ̈̈nlerinde süslü atlardan sonra sünnet çocuklarını arabalarla gezdirmek, Osmanl toplumunun birçok yerinde yaygın bir âdet olarak rastlanılmıştır. İzmir bu âdetin yer alarak yaygınlık kazandı̆̆ sünnet dügününden bir gün önce arabalar tutularak çocuklar gezdirilirken, kafile önünde diz altında şalvarı kesik, yırtık başında rengârenk bir külah, elinde tef ile türlü türlü maskaralıklar yapan bir Yahudi soytarı, ardından çalgıcıların arabası, sonra sünnet olacak çocuğun arabası ve diğer sünnet olacak çocukların arabası şeklinde bir gezi düzenlenirdi"' (Moral1, 1976, s. 17-18).
} 
günde türbesi ziyaret ettirilirdi (Bayri, 1972, s. 170). Baz1 kurumlarda sünnet düğünlerinde türbe ziyaretleri için izin istenirdi. Eyüp’teki Takyeci Mahallesinde bulunan Darül-Feyz Mektebinde okuyan 30 kimsesiz çocuğun Eyüp camisine götürülüp ziyarette bulunulması için izin istenilmesi (BOA, DH. MKT 1644/ 20, 18 Temmuz 1305/1889) bu duruma örnek teşkil etmektedir. Eyüp türbe ziyareti dönüşünde Eyüp oyuncakçılarından oyuncak satın alınarak, çocuklar tarafından sevilen bir sünnet âdeti gerçekleştirilmiş olurdu (Göktaş, 1994, s. 114).

Sünnet düğünlerinde sünnetçi, çengi heyetleri, hokkabazlar ve aşçı düğünden bir gün önce sünnet edilecek çocuğun evine gelerek, ayrı ayrı odalarda takımlarını çıkarır ve hazırlıklarını tamamlarlardı (Bayri, 1953, s. 777). Sünnet çocukları sadece tanınmış sünnetçiler tarafindan değil aynı zamanda üfürükçülük, hekimlik gibi hünerleri olan Abdallar tarafından da sünnet edilirdi (Ülkütaşır, 1968, s. 252). Sünnet merasimi açısından, çocuk geniş bir kıyafet giydirilerek babası ve yakınlarından diğer erkeklerle önceden hazırlanan ve sünnetçinin hazır bulunduğu odaya götürülür ve sünnet uygulaması gerçekleştirilirdi (Bayri, 1953, s. 777). Sünnet uygulamasının ardından yaranın iyileşmesi için ampirik bir yöntem olan odun külü kullanılırdı ${ }^{4}$ (Lewis, 1973, s. 102).

Sünnet düğ̈̈nlerinde önemli âdetlerden biri de hediye merasimiydi. Çocuklar sünnet edilip, yatağa yatırıldıktan sonra hediye merasimi başlardı. Sünnet olan çocuğun ailesi ve gelen misafirler çocuklara altın saatler, kordonlar, oyuncaklar, yazı takımları hediye ederlerdi (Celâl, 1946, s. 36). Hediye merasiminde farklı hediyeler de yer alırdı. Sermet Muhtar Alus 1898 yılında gerçekleşen sünnet düğününde fotoğraf albümü, dışındaki delikten anahtarla saat gibi kurulup ve iki şarkı çalan bir hediye geldiği (Akşam, 12 Kasım 1947, Sayı: 4) ifadesi ile bu farkl1lığı ortaya koymuştur.

Çeşitli hediyelerin yer aldığı sünnet düğünlerinde padişah, sultanlar ve şehzadelerde çocuklara para ve altın gibi ihsanlarda bulunurlardı. Mesela, 2. Abdülhamid 1908 y1lında Hamidiye Etfal Hastanesinde sünnetleri gerçekleştirilen çocuklara 80 lira ihsanda bulunmuştur (BOA, ML. EEM 677/35, 21 Mart 1324/1908 ). 1916 yılında 400 şehit ve asker çocuğunun

\footnotetext{
${ }^{4}$ Riza Nur'un eski usuldeki sünnetin kaza ve tehlikeleri, Fenni usulün faydaları ve bu usullerin mukayeselerine yer verdiği "SÜnnet Çocukları ve Ebeveyn Sünnetçiler ve Doktorlar" adlı eserinin 1908 yılında basımina izin verilerek (BOA, MF. MKT 1054/50, 30 Nisan 1324/1908) sünnet yöntemlerinde geleneksel usullerin yerine fenni usulün uygulanması ve toplumda yaygınlaşması açısından katkı sağlamış̧tır.
} 
sünnet edildiği toplu sünnet düğünün de ise Başkumandan Vekili Enver Paşa'nın eşi Naciye Sultan tarafından çocuklara 9 bin kuruşluk hediye verilmiştir (Servet-i Fünun, 17 Ağustos 1916, Sayı: 1313). Sünnet dügünlerinde sünnetleri gerçekleştiren kişilere yönelikte ihsanlarda bulunulmuştur. Hamidiye Etfal Hastanesinde çocuklarla birlikte bu çocukları sünnet eden doktorlara da ihsanlarda bulunulmuş (BOA, ML. EEM 350/61, 27 Eylül 1316/1900). Yine Hacı Mahmud Efendi'ye Çatalca ve Büyükçekmece'de fakir ve yetim çocukları ücretsiz sünnetini gerçekleştirdiği için nişan ve madalya verilmiştir (BOA, DH. MKT 2259/88, 10 Teşrin-i Evvel 1315/1899). Çocukların sünnetlerini gerçekleştirdiği için sünnetçilere ihsanlarda bulunulduğu gibi sünnetçiler de ücretsiz sünnet gerçekleştirmelerinden dolayı maaş talebinde bulunmuşlardır. Mesela, Diyarbakırlı Hakkı Efendi Anadolu'nun farklı noktalarında fakir çocukların ücretsiz sünnetlerini gerçekleştirdiğinden dolayı maaş talebinde bulunmuştur (BOA, ŞD 2479/13, 3 Nisan 1300/1884).

Toplumda yaygın olan âdetlerin yer aldığı sünnet düğünleri çeşitli kurumlarda özellikle cülûs-u hümâyun günü gerçekleştirilirdi. Mesela, 1902 y1lında Hadika-i Marifet, Necmi Terakki, Mekteb-i Osmani ve Dar'ül İrfan mekteplerinde cülûs-u hümâyun dolayısıyla çocuklar sünnet edilerek, ihsanlarda bulunulmuştur (BOA, ML. EEM 416/83, 17 Haziran 1918/1902).

Çocukların sünnet merasimi kurumlar açısından hastanelerde $\mathrm{de}^{5}$ gerçekleştirilerek bu merasimler açısından farklı seçenekler ortaya konulmuştur. Özellikle Hamidiye Etfal Hastanesinde cülûs-u hümâyun yıldönümleri dolayısıyla çocuklar sünnet ettirilip hediyeler verilmesi ve masraflarının karşılanması sürekli hale getirilmiştir. Cülûs-u hümâyunun 31. yıldönümünde Hamidiye Etfal Hastanesi'nde çocukların sünnet ettirilerek, masraflarının karşılanması (BOA, ML. EEM 568/61, 4 Teşrin-i Evvel 1322/1906) bu sürekliliğe örnek teşkil etmektedir.

\section{TOPLU SÜNNET DÜĞÜNLERİ}

Osmanlı Devleti'nde toplumsal dayanışma örneklerinden biri de toplu sünnet dügünleridir. $\mathrm{Bu}$ dügünlerde sünnet olacak çocuklarla beraber fakir aile çocukları da sünnet ettirilirdi (Okay, 1998, s. 92). Toplumda yaygınlık kazanan bu sünnet dügünleri açısından Tüfengiyan Ahmed

5 Çocukların sünnet merasimleri farkl hastanelerde de gerçekleştirilmiştir: “Bahriye Merkez Hastanesinde 1899 yllında Bahriye Sibyan tabur askerinden 13 çocuğun sünneti (BOA, Y. PRK. ASK 151/52, 13 Mayıs 1315/1899), Haydarpaşa Hastanesinde 1891 yılında Üsküdar, Kadıköy ve civarında çocukların sünnetleri gerçekleştirilmişti’’ (BOA, Y. PRK. AZJ 19/27, 18 Mayıs 1307/1891). 
Efendi'nin oğlu İsmail'in Seyyid Ahmed Mahallesindeki evinde gerçekleştirilen sünnet düğününde 4-5 çocuğun davetliler ve çalg1 eşliğinde sünnet ettirilmesi (BOA, Y.PRK. ZB 21/28, 9 Haziran 1314/1898) örnek teşkil ettiği gibi toplu sünnet düğünlerine verilen önem açısından İstanbul'da yangın tulumbacıları her sene semtlerinin 3-5 fakir aile çocuğunu düğün masrafları için zengin insanlardan bahşiş toplayarak sünnet ettirirlerdi. $\mathrm{Bu}$ sünnet düğünlerinde çocuklarla birlikte sünnet olmayan yetişkin kişiler de sünnet ettirilirdi (Koçu, 1969, s. 210). Sünnet olmayan yetişkin kişilerin sünnet edilmesi âdeti dönemin sünnetçilerinin anılarında da yer almıştır. Mesela, dönemin ünlü sünnetçilerinden Hacı Hüseyin Bey, Selçuk Hatun'da 150 çocukla birlikte 40 yaşında bir yetişkini sünnet ettiğini (Son Posta, 5 Ağustos 1934, Sayı: 1448) ifade ederek toplu sünnet düğünlerinde toplumda yaygın olan bir âdeti ortaya koymuştur. Yetişkin kişiler Osmanlı kurumlarında görev almak maksadıyla da sünnet ettirilirdi. Rusya'dan göç ederek Düzce'ye yerleştirilen Abazalardan birkaç kişi zaptiye olmak için sünnet ettirilmesi (Son Posta, 13 Mart 1932, Sayı: 587) yetişkin kişilerin sünnet edilmesinin farklı bir yönünü ortaya koymaktadır.

Önemli günler açısından toplu sünnet düğünleri hanelerin bazı kuruluşların açılış merasimi dolayısıyla gerçekleştirilirdi. Edirne'de Piyade Kışlasının açı1ış merasimi dolayısıyla 160 asker çocuğu sünnet ettirilmiş (BOA, Y.PRK. UM 25/90, 16 Teşrin-i Sani 1308/1892) yine cülûs-u hümâyun yıldönümünde Hereke fabrikasında inşa ettirilen Çuka fabrikasının açılması dolayısıyla fakir çocuklar sünnet ettirilmiştir (BOA, ML. EEM 482/94, 21 Temmuz 1320/1904).

Toplu sünnet düğünlerinde fakir aile çocuklarının yanında şehit ve asker çocukları özellikle padişahın cülûs-u hümâyun veya doğum günü yıldönümlerinde sünnet ettirilerek eğlencelere yer verilirdi. Selanik ve Kosova'da asker ve şehit aile çocukları cülûs-u hümâyun dolayısıyla sünnet edilip, ihsanlarda bulunulmuş (BOA, ML. EEM 236/ 61, 28 Temmuz 1312/1896). 1916 yılında ise Hilal-i Ahmer hastanesinde 400 kişilik şehit ve asker aile çocukları sünnet konusunda bilgi ve becerileri olan doktorlar tarafindan toplu sünnet edilip toplumda yaygın olan âdetten hareketle sinema, hokkabaz, kukla gibi eğlencelerin yer aldığ fasıllara da yer verilerek (Servet-i Fünun, 17 Ağustos 1916, Say1: 1313) hem toplumda yaygın olan âdet gerçekleştirilmiş olur hem de padişahın cülûsu hümâyunu dolayısıyla şenlikler yapılarak toplumsal eğlence sağlanmış olurdu (Felek, 1974, s. 104).

Fakir, şehit ve asker aile çocukları Darüşşafaka, Darülaceze, Dârülhayr-i Ali gibi 2. Abdülhamid'in çocukları himaye ettiği ve destek verdiği kurumlarda da toplu sünnetleri gerçekleştirilirdi. 
Darüşşafaka mektebinde 1902 y1lında Altıpoğaça mahallesinden birkaç çocuk sünnet edilerek 2. Belediye Dairesi doktorlarından Hakkı Bey tarafindan tedavi edilmiş̧ir (BOA, Y. PRK. ŞH 8/69, 3 Haziran 1315/1899).

Darülaceze'de 1901 y1lında cülûs-u hümâyun yıldönümünde 20 çocuğun sünnetleri gerçekleştirildiği gibi (BOA, DH.MKT 2094/5, 10 Ağustos 1314/1898) yine 1903 yıllnnda cülûs-u hümâyun y1ldönümünde çocuklar sünnet ettirilerek masrafları karşılanmıştır (BOA, DH. MKT 2544/154, 2 Teşrin-i Evvel 1317/1901).

Dârülhayr-i Ali'de 1903 yılında 20 çocuğun sünnetleri gerçekleştirilerek 100 kuruş hediye verilmiştir (BOA, ML. EEM 453/58, 21 Teşrin-i Evvel 1913/1903).

Şehit ve asker aile çocuklarının toplu sünnet dügünleri çocuklara verilen önemin bir işareti olarak savaş döneminde de gerçekleştirilmiştir. Mesela, Çocukların bakım ve korunması konusunda büyük katkı sağlayıp başarılar elde eden Kazım Paşa öncülüğünde 14 Ağustos 1920 tarihinde şehit ve asker çocuklarının sünnet kıyafetleri giyindirilip, çalgı ve araba ile şehri dolaştırıldığı toplu sünnet düğünleri Erzurum Sanayi Gürbüzleri binasının bahçesinde gerçekleştirilerek toplumda yaygın olan eğlencelere yer verilmiştir (Karabekir, 1995, s. 72-73-74).

Şehit ve asker aile çocuklarının toplu sünnet dügünlerinde sünnet âdetleri gerçekleştirildiği gibi bir miktar kazanç elde edilerek bu kazançların bir kısmı kurumlara bağışlanmıştır. Hilal-i Ahmer Cemiyeti bağış yapılan kurumlardan biri olup, 1921 yılında Şehremaneti Mehmet Ali Bey, himayesinde Pangaltı Osman Bey gazinosunda şehit ve fakir ailelerin çocuklarının sünnetleri gerçekleştirilerek elde edilen kazancın yarısı Hilal-i Ahmer Cemiyeti'ne bağışlanmıştır (Tasvir-i Efkar, 7 Haziran 1921, Sayı: 63034).

Belirlenen noktalara yerleşip yardımlarda bulunulan muhacir çocuklar için de toplu sünnet dügünlerinin gerçekleştirilmesi dönemin çocuk politikalarını yansıtması açısından dikkate değer mahiyettedir. Özellikle yetim muhacir çocuklar Muhacir dulhanesinde barındırılıp mektebe gönderilerek koruma altına alındığı gibi sünnet merasimleri de gerçekleştirilmiştir. 1885 yılında muhacir çocuklardan 15-20 sinin sünnetleri gerçekleştirilmiş (BOA, Y. MTV 18/09, 27 Mayıs 1301/1885). Yine Hamidiye köyünde yerleştirilen Silistre muhacir ve çevredeki çocuklarla birlikte 60 çocuk (BOA, Y. A. HUS 182/44, 13 Haziran 1301/1885) Sis'e yerleştirilen Girit muhacirlerinden 50 çocuk sünnet ettirilmiştir (BOA, DH. MKT 2428/1, 1 Teşrin-i Sani 1316/1900). 
2. Abdülhamid çeşitli vesilelerle kişi ve kurumlara yönelik ihsanları sünnet düğünleri vesilesi ile muhacir çocuklar için de bulunmuștur. Dönemin yaygın olan bu uygulamasinda 2. Abdülhamid 10 Haziran 1879 tarihinde sünnetleri yapılacak muhacir çocuklar için Muhacirin İdaresi Veznesine teslim edilmek üzere ihsanlarda bulunmuştur (BOA, Y. PRK. KOM 1/81, 29 May1s 1295/1879)

\section{SÜNNET EĞLENCELERI}

Osmanlı toplumunda eğlence kültürünün önemli bir unsuru olan sünnet dügünlerinde 3-4 türlü eğlenceye yer verilirdi (Felek, 1974, s. 108). Sünnet eğlencelerinde, misafir ve çocukları eğlendirmek için Kanarya, Çiçekçioğlu, Sabatay, Kuzguncuklu Yasef, Salomon'un Takımı diye ün yapmış Musevi hokkabazlardan biri ile yine Karagöz oyunu için Cerrah Salih Efendi, Şeyh Tahir Efendi, Agah Efendi, Müezzin Mehmet Efendi, Ortaköylü Osep Efendi, Sait Efendi, Fehmi Efendi, Saraç Yahya Efendi gibi döneminin usta hayalcilerden birisi ile sünnet günü için anlaşma yapılırdı. $\mathrm{Bu}$ eğlenceler dışında orta oyunu, zuhuri kolu ve meydan oyununu oynayan Kör Mehmed, Hacı Bekçi, Çifte Kanburlar, Küçük Mehmed, Han Kolu gibi meşhur takımlardan birisi ile çalgı takımı olarak büyük ilgi duyulan ve beğenilen hanendelerden bir takım seçilerek anlaşılırdı (Abdülaziz Bey, 1995, s 41-42).

Sünnet düğününde eğlenceler günler öncesinden başlardı. Günler öncesi başlayan eğlencelerde çalgı ekibi önemli yer tutmuş olup, yapılan eğlenceleri Mehmet Şakir Ülkütaşır şu şekilde ifade etmiştir:

"Düğün gürültü̈sü, koşuşturmacalar ve sevinç sırasında İstanbul'un en usta zurnacisl Arap Mehmet takımı sünnet düğününden dört beş gün önce köşke gelip, iki zurna, bir klarnet çiftenaraların düğümleri arasında fasıla başlatarak, zurnacılar İstanbul'un en kivrak, oynak türkülerini çalmaya başladılar. Arap Mehmet takımı sünnet düğününe kadar sabah ögle ve akşam çalgl çigane yaşatır; bizi eğlendirirdilerdi" (Ülkütaşır, 1979, s. 4-5).

Düğün günü önceden anlaşılmış olan hokkabaz, hayalci, karagöz sanatçıları erkenden sünnet düğününün yapılacağı eve gelerek, kendileri için ayrılmış odada hazırlıklara başlardı (Göktaş, 1994, s. 114). Tüm bu hazırlıklardan sonra eğlenceler sünnet edilecek çocuğun sünnet odasına getirilerek hokkabazların bu oda önünde zilli deflerle "Oldu da bitti Maşallah iyi olur İnşallah" diyerek çocuğun feryadını gürültüye getirip sünnet olacak diğer çocukların ses duymasını engellemiş olmasıyla başlardı. 
(Felek, 1974, s. 108). Eğlenceler çocukların sünnet edilerek yataklarına yatırılıp, misafirlerin kendilerine ayrılan kısımlara yerleşerek hokkabazların gösterilerini gerçekleştirmeleri ile devam ederdi. $\mathrm{Bu}$ eğlencelerde hokkabazlar oyun takımlarını bir zembil ile masanın altına koyup, defler çalarak gösterilerde hoşa gidecek ve çocukları avutacak tuhaflıklarla hem çocukları hem de misafirleri güldürürlerdi (Abdülaziz Bey, 1995, s. 48-49).

Hokkabazların gösterisi ve yemek faslından sonra seyirlik oyunlar ile eğlencelere devam edilirdi. Kavuklu ve Pişekâr ile güldürü ögesinin hâkim olduğu seyirlik oyunları Abdülaziz Bey şu şekilde ifade etmiştir:

"Zuhuri kolu denen bu oyunlarda bir Kavuklu, bir Pişekâr, Zenne kiliğına girmiş iki kişi ile oyunun icabına göre Acem, Laz, Vanl Ermeni, Kastamonu'da yeni gelmiş bir adam, Arap, Frenk, Arap Halayık, sarhoş rollerini yapanlardan ibarettir. Bunlar kıyafetlerini giydikleri halkın tavır ve lisanını taklit ederek tertiplenmiş oyunu oynarlar. Bu oyun gerçekten hoştur ve herkesi güldürür ve eğlendirir. Oyun iki saat kadar devam eder, sonunda da harem ve selamlıkta saz takımı gösterilerine başlardı (Abdülaziz Bey, 1995, s 50).

Saz ve çengi oyunları ile devam eden eğlencelerde hokkabazlar bir kez daha hünerlerini gösterirlerdi (Bayri, 1953, s. 778). Sünnet dügünlerinde eğlenceler, gündüz kadınlara gece ise erkeklere ayrılırdı (Bayri, 1953, s. 778).

Geceleyin sünnet düğününün eğlenceleri anlarından biri olarak Karagöz oyunu oynatılırdı (Ekrem\&Fehmi, 1945, s 25). "Hayal oyunu” denilen ve çocuklarla kadınların karşısına perdeler kurularak Hacivat ve Karagöz'ün ana karakter olarak oynatıldığ Hacivat ile Karagöz arasında hoş ve gülünç sohbetlerin geçtiği bu oyunun ardından Hokkabaz bir fasıl daha oynayarak (Abdülaziz Bey, 1995, s. 51) eğlenceler sabaha kadar devam ederdi.

Sabaha karşı oynanan "Ateş" adlı oyun sünnet düğünlerinde ilginç ve eski âdetlerinden biriydi. Bu oyunda hokkabaz kıyafetlerini çıkararak ufak bir değnek ucuna pamuk yumaklarını ispirtoya batırıp kendilerine ya da birbirlerinin sırtına vurarak tuhaf tavırlar ile eğlenceli konuşmalar yaparlardı (Abdülaziz Bey, 1995, s 51). Bu oyun ile toplumun eğlence kültürünün önemli bir örneğini teşkil eden sünnet düğünlerinde ilk gün eğlenceleri sona ererdi. 
Sünnet düğününde eğlenceler üç gün devam ederdi. İkinci gün devam eden eğlenceleri yalnız hane halkı ve akrabaların karşısında evin harem kısmında 'Sıracılar' denilen kadın çalgıcıların gösterileriyle başlardı. Çengiler ve saz çalan kadınlar ve cariyelerin saz ve dans gösterilerinin ardından hanede bulunan kadınların çeşitli gösterilerine yer verilirdi. $\mathrm{Bu}$ gösterilerden biri de, bir kadın koyun postuna sarınıp başına bir ip takarak dört ayak üzerine yürür, tuhaflıklar yapardı (Abdülaziz Bey, 1995, s. 53).Bu eğlencelerin yanı sıra toplu sünnet dügünlerinde pehlivan güreşleri, jimnastik oyunları, zeybek oyunu gibi eğlencelerde yer alırdı (Bayri, 1953, s 778). Bu eğlencelerle birlikte sünnet düğünleri son bulurdu.

Sünnet düğünlerinde eğlenceler önemli yer tutmasına rağmen kutsal mekânlara yakın yerlerde yapılacak sünnet dügünleri için izin alınarak eğlencelere devam edilirdi. Nitekim böyle bir engel Eyüp Sultan'a yakın bulunması sebebiyle Topçular Köyü civarında Şifahavuzu adlı mekânda fakir çocukların sünnet ettirilip eğlenceler düzenlenmesiyle meydana gelmiş, izin alınmak suretiyle eğlencelere devam edilmiştir (BOA, DH. MKT 1536/40, 15 Ağustos 1304/1899).

Sünnet eğlencelerin de birtakım zararlı olaylar yaşanmıştır. Nitekim, sünnet düğünlerinin yapıldığı mekanlarda yangın, çökme gibi birtakım olaylar yaşanmakta ve ölümlere sebebiyet verdiğinden dolay1 1899 yılında köy ve kasabalarda bu gibi olaylarda zararların önlenmesi için mahalli idarelerce gerekli tedbirler alınması istenilmiştir (BOA, DH. MKT 2220/37, 27 Haziran 1315/1899).

Sünnet eğlenceleri çocukların sünnetlerinin gerçekleştirildiği hastanelerde de yapılmaktaydı. 1907 y1lında Hamidiye Etfal Hastanesinde padişahın doğum gününde çocuklar sünnet ettirildiği gibi, sünnet eğlenceleri için saz takımı, hokkabaz, hayalci, çalgıcı ve kuklacılar ile eğlenceler düzenlenerek, bu merasimler için 282 kuruş ödenmiştir (BOA, ML. EEM 637/65 19 Teşrin-i Evvel 1322/1907).

\section{OSMANLI SARAYINDA SÜNNET DÜĞÜNLERİ}

Padişahların erkek çocuklarının sünnetleri ile kızlarının, kız kardeşlerinin ve yeğenlerinin evlendirilmesi sırasında yapılan düğünlere Sûr1 Hümâyun denilirdi. Sünnet dügünlerine Sûr-i Hitan adı verilip bu düğünlerde görkemli ve uzun süreli şenlikler ${ }^{6}$ yapılırdı (And, 1994, s. 77).

6 "'Sûr-ı Hümâyun bir zaferin kazanılması, bir kalenin düşmandan ele geçirilmesi, sultanın cülûsu ya da cülûs yıldönümü, şehzadelerin okumaya başlaması, saraydaki doğumlar içinde düzenlenirdi. Kimi kez iki vesile ile birleştirilirdi. İki düğün bir 
Klasik dönemden itibaren sultanların evlilik ve şehzadelerin sünnet düğünlerinin yapıldığg (Nutku, 1994, s. 17) merasimler Osmanlı Devleti’nin son dönemine kadar devam etmiştir. 2. Abdülhamid döneminde ilk olarak Abdülmecid, Mehmed Şevket, Mehmed Seyfettin Efendilerin, ardından Abdülkadir, Ahmed, Burhaneddin Efendi ile Ahmed Nihad Efendi, son olarak da Abdürrahim Efendi, Cemaleddin Efendi, Abdülhalim Efendinin sünnet düğünleri gerçekleştirilmiştir (Osmanoğlu, 1986, s. 72-73). Saraydaki bu sünnet dügünlerinde eğlencelerde düzenlenmekteydi. Karagöz ve Hokkabaz gösterileri ile Abdürrezak Efendi tarafından oynanan oyunlar vesilesiyle çocuklar ve misafirler eğlendirilirdi (Osmanoğlu, 1986, s. 73). Saray sünnet eğlenceleri arasında müzik faslı da önemli yer tutmaktaydı. 1882 yılında gerçekleşen sünnet dügününde ziyafet sırasında müzik faslına yer verilmesi (BOA, Y.PRK. HH 9/43, 25 Mart 1298/1882) bu önemi ortaya koymaktadır. Saray sünnet eğlenceleri 1913 yılında Beylerbeyi Sarayında, Sultan Mehmed Reşad'ın izni doğrultusunda (Son Posta, 28 Ekim 1931, Sayı: 453) gerçekleştirilen Âbit Efendinin sünnet düğününde de yer verilerek Karagöz, çalgı takımı gösterileri ile eğlenceler sabaha kadar devam etmiştir (Son Posta, 2 Kasim 1931, Sayı: 457).

Sarayda büyük hazırlıklarla yapılan sünnet düğünlerinde şehzadelerle birlikte fakir aile çocukları da sünnet ettirilirdi. Bu durum 2 . Abdülhamid döneminde de devam ederek süreklilik kazanmıştır (Türkoğlu, 1997, s. 110). 2. Abdülhamid döneminde sünnet düğünlerinde Yıldız'da hususi barakalar hazırlanarak, sünnet edilen çocuklar 5 gün sarayda kalarak tedavi edilmiştir (Osmanoğlu, 1986, s. 73). Saraydaki sünnet dügünlerinde şehzadelerle birlikte saray çalışanlarının çocukları da sünnet edilmiştir. Şehzade Abdürrahim Efendi'nin sünnet dügünü dolayısıyla çocuklarını sünnet ettirmek isteyen saray mensuplarının durumu bildirmesi istenerek (BOA, İ.HUS 75/57, 21 Mayis 1315/1899) toplumda yaygin bir uygulama olan toplu sünnet dügünleri Osmanlı sarayında da yer verilmiştir. 1899 yılında şehzadelerin sünneti vesilesiyle sarayda çeşitli görevlerde yer alan 121 kişinin çocuğu Gümüşsuyu Hastanesinde sünnet ettirilmesi (BOA, TSMA. E 625, 22 Mayıs 1315/1899) bu uygulamaya örnek oluşturmaktadır.

Osmanlı Devleti'nde sarayların dışında şehzade konaklarında da sünnet merasimleri yapılırdı. Mesela, Sultan Vahdeddin döneminde şehzade Yusuf İzzeddin Efendinin oğlu Nizameddin Efendinin sünneti Yusuf İzzeddin Efendi'nin konağında gerçekleştirilmiştir. Toplumda ve sarayda yaygın bir uygulama olan yatakların ve kıyafetlerin süslenmesi bu sünnet

araya getirilirdi'”. (And, 1994, s. 71). 
düğününde gerçekleştirilerek 50 fakir ve yetim çocuk sünnet ettirilmiştir (Ünüvar, 1964, s. 133-134).

Sarayda şehzadeler ile birlikte toplu sünnetlerinde gerçekleştirildiği Sûr-1 Hümâyunda ziyafetler verilirdi. Sünnetlerde ziyafet verilmesine 2. Abdülhamid devrinde gerçekleşen sünnet dügünlerinde yer verilerek süreklilik kazanmıştır. 1882 yılında Mehmed Şevket, Mehmed Seyfettin Efendilerin sünnet dügünleri vesilesiyle 1500 çocuğun kıyafet ve diğer masrafları karşılanarak ihsanlarda bulunulduğu toplu sünnet düğ̈nünde ziyafetler verilmiş (BOA, Y. PRK. HH 9/43, 25 Mart 1298/1882) Yine şehzade Abdürrahim Efendi'nin sünnet töreni vesilesiyle ziyafet verileceği bildirilmesi (BOA, DH. MKT 2209/144, 31 Mayıs 1315/1899) bu sürekliliğgi ortaya koyması açısından dikkate değerdir.

Saraydaki sünnet dügünlerinde son dönemde Osmanlı saray ve toplumunda yaygınlık kazanan fotoğraf geleneğine de yer verilmiştir. 1897 yılında gerçekleştirilen sünnet dügününde şehzade Abdürrahim Efendi, şehzade Cemalettin Efendi, şehzade Abdülhalim Efendiyi ve muhafızları Ziya Bey ve Ali Fuad Bey ile birlikte gösteren fotoğraflar bu geleneğin bir sonucudur (Çizgen, 1993, s. 77).

\section{SONUÇ}

19. yüzy1l öncesinde sarayda şehzadeler için yapılan sünnet düğünlerinde hazırlıklara, eğlencelere, toplu sünnet düğünlerine yer verilen surnâmeler dişında sünnet dügünleri açısından ayrıntılı bilgiler yer almamaktayd. Fakat 19. yüzyılda yaşanan yenilikler ve değişim Osmanlı Devleti'nde toplumun bir unsuru olan çocuk üzerinde de etkisini göstererek çocuğa bakış açısının ortaya konması açısından sünnet dügünleri önem arz etmekteydi.

Düğün gününün kararlaştırılması ile başlayan hazırlıklar, toplumda yaygın olan inançlardan hareketle sünnet günü, davetiye, kıyafet gibi hazırlıkların tamamlanması ile devam ederdi. Hane ve çeşitli kurumlarda geleneksel usullerin uygulandığg sünnet merasimlerinde, Karagöz, Hacivat, Hokkabaz, Çengi ve saz takımları gibi birçok eğlencelerin yer aldığı sünnet düğünleri dönemin sosyo-kültürel, ekonomik, siyasi, folklor gibi birçok alanda bilgiler vermekteydi.

Fakir, asker ve şehit aile çocukları ile muhacir çocukların sünnetlerinin gerçekleştirildiği ve önemli günlerin tercih edildiği toplu sünnet düğünleri de toplumsal dayanışma ve yardım açısından padişah, sultan ve şehzadelerin desteklemesi bu eğlence kültürünün çok yönlü 
fonksiyonunu ortaya koymaktadır.

Sarayda gerçekleştirilen sünnet düğünlerinde toplumda yaygınlık kazanan toplu sünnet düğünleri, eğlence ve ziyafet gibi âdetler gerçekleştirilerek çocuk politikaların başka bir yönünü ortaya koymaktadır.

Eğlence kültürü açısından sünnet dügünleri çok yönlü işlevi ile çocuk konusuna bilgi açısından katkı sağlayarak, önemli bir kaynak teşkil etmektedir.

\section{KAYNAKLAR}

Abdülaziz Bey, (1995). Osmanlı âdet, merasim ve tabirleri toplum hayatı. Haz. Kâzım Arısan, Duygu Arısan Günay, İstanbul: Tarih Vakfı Yurt Yayınları. Akşam, 12 Kasım 1947, Sayı: 4.

And, M. (1994). Sur-1 Hümayun. Dünden Bugüne İstanbul Ansiklopedisi VII, 71-72. Apaydın, A. (2018). Osmanlı'da çocuk olmak. Yedikıta, 123, 18-37.

Arslan, M. (2007). Kültür tarihimiz açısından zengin bir kaynak: Sûr-nâmeler. Türkiye Araştırmaları Literatür Dergisi, 10, 221-258.

Aynur, H. (2009). Sûrnâme. Türkiye Diyanet Vakfi İslam Ansiklopedisi, XXXVII, İstanbul, 565-567.

Bayat, A. H. (1982). Osmanlı devri saray sünnet şenlikleri (Sûr-1 Hümâyunlar). Kubbealtı Akademi Mecmuası, 3, 53-76.

Bayat, A. H. (1982). Osmanlı imparatorluğu Türkiye'sinde saray dışı sünnet merasimleri. II. Milletlerarası Türk Folklor Kongresi Bildirileri kitabı içinde (ss. 11-20), Ankara: Kültür ve Turizm Bakanlığı.

Bayri, M. H. (1953). İstanbul'da sünnet dügünleri. Türk Folklor Araştırmaları, 49, 776-778.

Bayri, M. H. (1972). İstanbul folkloru, İstanbul: Eser Yayınları.

Çağatay, N. (1972). 100 soruda İslâm tarihi, İstanbul: Gerçek Yayınevi.

Çizgen, E. (1993). Osmanlı dönemi fotoğraflarında çocuk. Toplumsal Tarihte Çocuk sempozyumu bildiriler kitabı içinde (ss. 76-84) İstanbul.

Ekrem, E. \& Fehim, M. (1945). Dünden hatıralar, İstanbul, Yedigün Neşriyatı.

Felek, B. (1974). Yaşadı̆̆ımız günler, İstanbul: Milliyet Yayınları.

Göktaş, U. (1994). Sünnet adetleri. Dünden Bugüne İstanbul Ansiklopedisi, VII, 113-114

Gürkan, S. L. (2010). Sünnet. Türkiye Diyanet Vakfi İslam Ansiklopedisi, XXXVIII, $157-159$

İkdam, 13 Ağustos 1920, Say1: 8430.

Karabekir, K. (1995) Çocuk davamız 1, Yay. Haz: Faruk Özerengin, İstanbul: Emre Yayınları.

Koçu, R. E. (1969). Sünnet takkesi. Türk Giyim Kuşam ve Süsleme Sözlüğü. Ankara: Sümerbank Kültür Yayınları.

Lewis, R. (1973). Osmanl Türkiye'sinde gündelik hayat (adetler ve gelenekler) İstanbul: Doğan Kardeş Yayınları. 
Moralı, N. (1976). Mütarekede İzmir, İstanbul: Tekin Yayınevi.

Musahipzade, C. (1946). Eski İstanbul yaşayışı, İstanbul: Türkiye Yayınevi.

Nutku, Ö. (1993). Osmanlı şenliklerinde çocuk. Toplumsal Tarihte Çocuk, sempozyumu bildiriler kitabı içinde (ss. 57-64). İstanbul.

Okay. C. (1998). Osmanlı çocuk hayatında yenileşmeler 1850-1900, İstanbul: Kırkambar Yayınları.

Osmanoğlu, A. (1986). Babam Sultan Abdülhamid, Ankara: Selçuk Yayınları.

Pakalın, M. Z. (1972). Sünnet düğünü. Tarih Deyimleri ve Terimleri Sözlüğü III, İstanbul: Milli Eğitim Basımevi.

Servet-i Fünun, 17 Ağustos 1916, Sayı: 1313.

Son Posta, 13 Mart 1932, Say1: 587.

Son Posta, 2 Kasim 1931, Say1: 457.

Son Posta, 28 Ekim 1931, Sayı: 453.

Son Posta, 5 Ağustos 1934, Say1: 1448.

Tasvir-i Efkar, 7 Haziran 1921, Sayı: 6-3034.

Türkiye Cumhuriyeti Cumhurbaşkanlığı Devlet Arşivleri Başbakanlığı Osmanlı Arşivi (BOA).

BOA, Y. PRK. KOM. 1/81. 29 May1s 1295/1879.

BOA, Y.PRK. HH./9/43. 25 Mart 1298/1882.

BOA, ŞD. 2479/13. 3 Nisan 1300/1884.

BOA, Y. MVT. 18/22. 27 May1s 1301/1885.

BOA, Y. A. HUS. 182/44. 13 Haziran 1301/1885.

BOA, DH. MKT. 1536/40. 15 Ağustos 1304/1888.

BOA, DH. MKT 1644/ 20, 18 Temmuz 1305/1889.

BOA, Y. PRK. AZJ 19/27, 18 May1s 1307/1891.

BOA, Y. PRK. UM. 25/90. 16 Teşrin-i Sani 1308/1892.

BOA, ML. EEM. 236/61. 28 Temmuz 1312/1896.

BOA, Y. PRK. ZB. 21/28. 9 Haziran 1314/1898.

BOA, DH. MKT. 2094/5. 10 Ağustos 1314/1898.

BOA, Y. PRK. ASK. 151/ 52. 13 Mayis 1315/1899.

BOA, TSMA. E. 625/22 May1s 1315/1899.

BOA, İ.HUS. 75/57. 21 May1s 1315/1899.

BOA, DH. MKT. 2209/144. 31 May1s 1315/1899.

BOA, Y. PRK.. ŞH. 8/69. 3 Haziran 1315/1899.

BOA, DH. MKT. 2220/37. 27 Haziran 1315/1899.

BOA, DH .MKT. 2259/88. 10 Teşrin-i Evvel 1315/1899.

BOA, ML. EEM. 350/61. 27 Eylül 1316/1900.

BOA, DH. MKT. 2428/1. 1 Teşrin-i Sani, 1316/1900.

BOA, DH. MKT. 2544/ 154. 2 Teşrin-i Evvel 1317/1901

BOA. ML. EEM. 416/83. 17 Haziran 1318/1902.

BOA. ML. EEM. 453/58. 21 Teşrin-i Evvel 1319/1903.

BOA, ML. EEM. 482/94. 21 Temmuz 1320/1904.

BOA, ML. EEM. 568/61. 4 Teşrin-i Evvel 1322/1906 .

BOA, ML. EEM. 574/73. 4 Teşrin-i Evvel 1322/1906. 
BOA, ML. EEM. 637/65. 19 Teşrin-i Evvel 1323/1907.

BOA, ML. EEM. 677/35. 21 Mart 1324/1908.

BOA, MF. MKT. 1054/50. 30 Nisan 1324/1908.

Türkoğlu, S. (1997). Osmanlı saraylarında çocuk. Çocuk Kültürü 1. Ulusal Çocuk Kültürü Kongresi Bildirileri, sempozyumu bildiriler kitabı içinde (ss. 105123). Ankara: Ankara Üniversitesi.

Ülkütaşır, M. Ş. (1968). Abdallar. Türk Kültürü̈, 64, 251-255.

Ülkütaşır, M. Ş. (1979). 70 yıl önce Erenköy'deki sünnet düğünleri. Türk Folkloru, 1, 3-6.

Ünüvar, S. (1964), Saray hatıralarım, İstanbul: Cağaloğlu Yayınevi.

Çatışma beyanı: Makalenin yazarı bu çalışma ile ilgili taraf olabilecek herhangi bir kişi ya da finansal ilişkileri bulunmadığını dolayısıyla herhangi bir çıkar çatışmasının olmadığını beyan eder.

Destek ve teşekkür: Çalışmada herhangi bir kurum ya da kuruluştan destek alınmamıştır. 